\title{
Carbon Dioxide Production in the Oxidation of Organic Acids by Cerium(IV) under Aerobic and Anaerobic Conditions
}

\author{
KARA BUTLER, OLIVER STEINBOCK,* BETTINA STEINBOCK,* NAR S. DALAL
}

Florida State University, Department of Chemistry, Tallahassee, Florida 32306-3006

Received 16 March 1998; accepted 2 June 1998

\begin{abstract}
The stoichiometry of $\mathrm{CO}_{2}$ production during the ceric oxidation of various organic acids is measured under conditions with organic acid excess. Measurements utilize a photometric methodology. For anaerobic conditions stoichiometries $\left[\mathrm{CO}_{2}\right]_{\text {produced }}$ : $[\mathrm{Ce}(\mathrm{IV})]_{\text {reduced }}$ of about 0 (malonic acid), 0.5 (e.g., glyoxylic acid), and 1.0 (oxalic acid) are found. Oxalic acid showed an oxygen-induced decrease of $\mathrm{CO}_{2}$ production, while other compounds such as malonic acid increased the amount of produced $\mathrm{CO}_{2}$ or showed no changes (e.g., tartronic acid). In the case of mesoxalic acid the stoichiometry is increased from about 0.5 to 2.0 due to the presence of molecular oxygen. The results are discussed on the basis of simple reaction mechanisms demonstrating that useful information on reaction pathways and intermediates can be extracted from these simple measurements. (C) 1998 John Wiley \& Sons, Inc. Int J Chem Kinet 30: 899-902, 1998
\end{abstract}

The study of oxidation of relatively low molecular weight carbonic acids by metal ions has been an active area of kinetics [1]. In particular the oxidation of malonic acid $\left(\mathrm{CH}_{2}(\mathrm{COOH})_{2}\right)$ and similar compounds by $\mathrm{Ce}(\mathrm{IV})$ in acidic solution have caught remarkable attention [2-5], since these reactions coincide with the organic subset of the self-organizing Belousov-Zhabotinsky (BZ) reaction [6]. Despite these efforts, the corresponding reaction mechanisms are not fully understood, because some of them are highly complex

*Present address: Otto-von-Guericke-Universität, Institut für Experimentelle Physik, Universitätsplatz 2, D-39106 Magdeburg, Germany

Correspondence to: O. Steinbock

Contract grant Sponsor: Deutsche Forschungsgemeinschaft

Contract grant Sponsor: Florida State University

Contract grant Sponsor: NATO Scientific Affairs Division

(C) 1998 John Wiley \& Sons, Inc. CCC 0538-8066/98/120899-04 and involve numerous organic acids and radicals as intermediates [4,7]. A common characteristic, however, is that most organic acids are oxidized to carbon dioxide. Hence, the determination of the stoichiometry between produced $\mathrm{CO}_{2}$ and reduced metal ions for the overall reaction mechanism reveals valuable information. A text book example is the ceric oxidation of malonic acid, where the overall reaction is written as [8]:

$$
\begin{aligned}
& \mathrm{CH}_{2}(\mathrm{COOH})_{2}+6 \mathrm{Ce}(\mathrm{IV})+2 \mathrm{H}_{2} \mathrm{O} \\
& \rightarrow \mathrm{HCOOH}+6 \mathrm{Ce}(\mathrm{III})+2 \mathrm{CO}_{2}+6 \mathrm{H}^{+} \text {. }
\end{aligned}
$$

While measurements of the overall $\mathrm{CO}_{2}$ stoichiometry are fairly frequent in the literature [9], we are not aware of systematic data on the $\mathrm{CO}_{2}$ production from oxidation experiments with large excess organic acid 
in which dissolved oxygen is explicitly considered. Under reaction conditions in which the organic acid is in excess, it can be assumed that only a small number of intermediates are formed. In other words, the relevant reaction mechanism is minimized to a few "starting" reactions of the complex overall mechanism. Most oxidation reactions between an organic acid $\mathrm{RH}$ and a metal ion $\mathrm{M}^{+\mathrm{n}}$ (e.g., $\mathrm{Ce}$ (IV) start with the formation of an organic radical $\mathrm{R} \cdot$ (e.g., the malonyl radical) $[1,2,7]$ :

$$
\mathrm{M}^{+n}+\mathrm{RH} \rightarrow \mathrm{M}^{+(n-1)}+\mathrm{R} \cdot+\mathrm{H}^{+} .
$$

The following reactions of the radical $\mathrm{R} \cdot$ leading to the first stable intermediate determine the stoichiometry $\mathrm{f}=\left[\mathrm{CO}_{2}\right]_{\text {produced }}:\left[\mathrm{M}^{+n}\right]_{\text {reduced }}$ between the amounts of produced $\mathrm{CO}_{2}$ and reduced metal ions in excess of organic acid. In this report the stoichiometry $\mathrm{f}$ is measured for ten organic compounds $(57<$ $M_{r}<183$ ) under anaerobic as well as aerobic reaction conditions. Cerium(IV) is used as the oxidizing agent. Measurements are performed on the basis of a photometric methodology [10]. The data obtained reveal interesting insights into the chemistry of the involved radicals and allow to some extent predictions on the identity of relevant intermediates. It is therefore felt that the presented approach is a useful aid for complementing other analytical techniques (e.g., NMR or EPR) that are sometimes difficult to apply.

All chemicals were obtained commercially (analytical grade) and used as received. Cerium(IV) sulfate, oxalic acid dihydrate, glyoxylic acid monohydrate, mesoxalic acid disodium salt, tartronic acid, L (-) malic acid, malonic acid, and glyoxal solution were obtained from Fluka. Chemicals purchased from Fluka include: tartaric acid, sodium hydroxide (N/10) solution, and sulfuric acid $(10 \mathrm{~N})$. Miscellaneous chemicals include: dihydroxy tartaric cid (Sigma), phenol red sodium salt (Aldrich), ferrous ammonium sulfate solution (0.1 N; LabChem), and citric acid (Mallinckrodt). All stock solutions were prepared from doubledistilled water.

With minor modifications the experimental setup is based on the earlier reported by Maxon and Johnson [10]. The key idea of this approach is to transfer the produced carbon dioxide from the sample into a basic phenol red solution (typically $200 \mathrm{ml}$ : [phenol red] = $\left.10^{-5} \mathrm{M},[\mathrm{NaOH}]=10^{-4} \mathrm{M}\right)$. According to the equilibrium between gaseous carbon dioxide and aqueous bicarbonate ion, the influx of $\mathrm{CO}_{2}$ gives rise to a $\mathrm{pH}$ change which is detected spectrophotometrically via the absorbance of phenol red. The detection limit for the system was about $2.2 \mathrm{mg} \mathrm{CO}$. Prior to each ex- periment the setup was calibrated by measuring the $\mathrm{CO}_{2}$ production of a $25 \mathrm{mM} \mathrm{NaHCO}$ solution which was acidified by injecting $1 \mathrm{ml}$ concentrated $\mathrm{H}_{2} \mathrm{SO}_{4}$. All oxidation reactions were carried out in $1.0 \mathrm{M}$ $\mathrm{H}_{2} \mathrm{SO}_{4}$ at $25.0 \pm 0.5^{\circ} \mathrm{C}$. Typical reactant concentrations were: $[\text { organic acid }]_{0}=0.1 \mathrm{M}$ and $[\mathrm{Ce}(\mathrm{IV})]_{0}=$ $1.9 \times 10^{-3} \mathrm{M}$. The $\mathrm{Ce}(\mathrm{IV})\left(\mathrm{SO}_{4}\right)_{2}$ stock solutions were titrated with $\mathrm{Fe}\left(\mathrm{NH}_{4}\right)\left(\mathrm{SO}_{4}\right)_{2}$ using ferroin as an indicator. The reaction solution (typical volume: 25-30 $\mathrm{ml}$ ) was equilibrated with either nitrogen or oxygen for 40 min prior to any measurement. Depending on the reaction conditions nitrogen or oxygen were also used as carrier gases for transfering the produced $\mathrm{CO}_{2}$ from the reaction vessel into the phenol red solution. For simplicity, we will denote reactions carried out with oxygen-saturated solutions as aerobic reactions.

Results for the stoichiometric value $\mathrm{f}=$ $\left[\mathrm{CO}_{2}\right]_{\text {produced }}:[\mathrm{Ce}(\mathrm{IV})]_{\text {reduced }}$ obtained under anaerobic and aerobic reaction conditions are summarized in Table I. For anaerobic reaction conditions six of the organic acids had a stoichiometry $f$ of approximately $1: 2$. Exceptions found are (i) oxalic acid which produces one mole of $\mathrm{CO}_{2}$ in the reaction with one mole of $\mathrm{Ce}(\mathrm{IV})$ and (ii) malonic acid which showed no significant $\mathrm{CO}_{2}$ production. In addition, citric acid gave rise to a surprising stoichiometry of approximately 0.35 . For comparison, we also studied the oxidation of the diketone glyoxal, which is obviously not likely to produce any carbon dioxide. Notice, that for anaerobic reaction conditions the results for malonic acid and glyoxal are identical.

The comparison between results obtained under anaerobic and aerobic reaction conditions reveals interesting differences for four of the organic acids (oxalic, mesoxalic, malonic, and citric acid). Oxalic acid decreases its $\mathrm{CO}_{2}$ production by a factor of two, while mesoxalic acid shows a large increase by a factor of about four. Malonic acid, the classic organic substrate of the Belousouv-Zhabotinsky reaction, and citric acid produce under the given aerobic reaction conditions carbon dioxide with a stoichiometry of approximately $f=1: 2$. The organic compounds glyoxylic acid, tartaric acid, malic acid, and glyoxal showed no significant dependence of the stoichiometry on the oxygen content of the reaction solution.

The presented results reveal three major stoichiometry values for the production of carbon dioxide: $\mathrm{f}=0.0,0.5$, and 1.0 . The value $\mathrm{f}=2$, found for mesoxalic acid, is only realized under aerobic reaction conditions. What are the underlying reaction mechanisms, which can give rise to these stoichiometries? As discussed in the Introduction, all of the studied reactions are likely to start with the formation of a radical R - (compare, R1). In the absence of molecular 
Table I Stoichiometric Ratios $\mathrm{f}=\left[\mathrm{CO}_{2}\right]_{\text {produced }} /[\mathrm{Ce}(\mathrm{IV})]_{\text {reduced }}$ under Anaerobic and Aerobic Reaction Conditions

\begin{tabular}{|c|c|c|c|}
\hline Organic Compound & Molecular Formula & $\mathrm{f}$ (anaerobic) & $\mathrm{f}$ (aerobic) \\
\hline Oxalic acid & $\mathrm{HOOCCOOH}$ & $1.03 \pm 0.05$ & $0.55 \pm 0.05$ \\
\hline Glyoxylic acid & $\mathrm{HCOCOOH}$ & $0.51 \pm 0.05$ & $0.45 \pm 0.05$ \\
\hline Mesoxalic acid & $\mathrm{HOOCCOCOOH}$ & $0.55 \pm 0.05$ & $1.97 \pm 0.1$ \\
\hline Tartaric acid & $\mathrm{HOOCCH}(\mathrm{OH}) \mathrm{CH}(\mathrm{OH}) \mathrm{COOH}$ & $0.45 \pm 0.05$ & $0.43 \pm 0.05$ \\
\hline Dihydroxy tartaric acid & $\mathrm{HOOCC}(\mathrm{OH})_{2} \mathrm{C}(\mathrm{OH})_{2} \mathrm{COOH}$ & $0.48 \pm 0.05$ & $0.51 \pm 0.05$ \\
\hline Tartronic acid & $\mathrm{HOOCHC}(\mathrm{OH}) \mathrm{COOH}$ & $0.49 \pm 0.05$ & $0.46 \pm 0.05$ \\
\hline Malic acid & $\mathrm{HOOCHC}(\mathrm{OH}) \mathrm{CH}_{2} \mathrm{COOH}$ & $0.43 \pm 0.05$ & $0.43 \pm 0.05$ \\
\hline Citric acid & $\mathrm{HOOCCH}_{2} \mathrm{C}(\mathrm{OH})(\mathrm{COOH}) \mathrm{CH}_{2} \mathrm{COOH}$ & $0.35 \pm 0.05$ & $0.50 \pm 0.05$ \\
\hline Malonic acid & $\mathrm{HOOCCH}_{2} \mathrm{COOH}$ & $<0.1$ & $0.48 \pm 0.05$ \\
\hline Glyoxal & $\mathrm{HCOCHO}$ & $<0.1$ & $<0.1$ \\
\hline
\end{tabular}

The stoichiometry $\mathrm{f}$ of carbon dioxide production in the ceric oxidation of small organic compounds with respect to the amount of reduced $\mathrm{Ce}(\mathrm{IV})$. Notice, that the initial amount of $\mathrm{Ce}(\mathrm{IV})$ is reduced completely, since the organic compound is in excess. Aerobic conditions correspond to an initial oxygen concentration of approximately $1.2 \mathrm{mM}$ (near saturation) and oxygen is also delivered during the entire course of the reaction.

oxygen, the following reaction scenarios are capable of generating the observed major stoichiometries.

In the simplest case, a radical recombination process takes place that produces a stable intermediate $R_{2}$ :

$$
\mathrm{R} \cdot+\mathrm{R} \cdot \longrightarrow \mathrm{R}_{2}
$$

Notice, that the stable product $\mathrm{R}_{2}$ could in principle react further with the oxidized metal ion, but would do this to no significant extent, since the organic acid $\mathrm{RH}$ is in large excess under the given experimental conditions. The resulting stoichiometry is therefore $\mathrm{f}=0$, as found for malonic acid. Indeed, Gao et al. [3] recently identified $R_{2}$ in the case of malonic acid as 1,1,2,2-ethanetetracarbonic acid.

The stoichiometry of 0.5 is one realization of the following reaction scheme:

$$
\begin{aligned}
& \mathrm{R} \cdot+\mathrm{R} \cdot \longrightarrow \mathrm{P}_{1}, \\
& \mathrm{P}_{1} \longrightarrow \mathrm{P}_{2}+\mathrm{m} \mathrm{CO}_{2},
\end{aligned}
$$

where $\mathrm{m}$ is a positive integer. In this scenario an unstable intermediate $\mathrm{P}_{1}$ is formed by radical recombination which then splits off $\mathrm{m}$ carbon dioxide molecules. The corresponding stoichiometry is therefore $\mathrm{f}=\mathrm{m} / 2$. Notice, that the process (R4b) might as well form more than one stable fragment, with one fragment being possibly the initial organic acid RH. In this case, the system performs a classic disproportionation. The oxidation of glyoxylic acid under anaerobic reaction conditions [11] is a simple example for this behavior

$$
\begin{aligned}
\mathrm{HCOCOOH}+\mathrm{Ce}(\mathrm{IV}) \longrightarrow & \cdot \mathrm{COCOOH} \\
& +\mathrm{Ce}(\mathrm{III})+\mathrm{H}^{+},
\end{aligned}
$$

$$
\begin{aligned}
2 \cdot \mathrm{COCOOH}+\mathrm{H}_{2} \mathrm{O} \longrightarrow & \mathrm{HCOCOOH} \\
& +\mathrm{HCOOH}+\mathrm{CO}_{2},
\end{aligned}
$$

and is obviously in good agreement with the measured stoichiometry of $\mathrm{f}=0.51$.

A different reaction mechanism could be realized in the case of the ceric oxidation of oxalic acid, where the stoichiometry is measured with $\mathrm{f} \approx 1.0$. One possible explanation could be based on the reaction scheme $\mathrm{R} 4 \mathrm{a} / \mathrm{R} 4 \mathrm{~b}$ with $\mathrm{m}=2$. An alternative way to describe this reaction, however, is to assume that the primary radical $\mathrm{R} \cdot$ splits off $\mathrm{CO}_{2}$ directly and forms a second radical species $\mathrm{S} \cdot$ :

$$
\begin{aligned}
& \mathrm{R} \cdot \longrightarrow \mathrm{S} \cdot+\mathrm{CO}_{2}, \\
& \mathrm{~S} \cdot+\mathrm{S} \cdot \longrightarrow \mathrm{S}_{2} .
\end{aligned}
$$

In the case of oxalic acid, $\mathrm{S}$ - would be the radical - $\mathrm{COOH}$ and $\mathrm{S}_{2}$ oxalic acid itself-a mechanism which is also in good agreement with the stoichiometric ratio of 2 between oxalic acid and $\mathrm{Ce}(\mathrm{IV})$. An additional reaction which could be of importance for the $\mathrm{Ce}(\mathrm{IV}) / \mathrm{oxalic}$ acid system involves the direct oxidation of the radical [12].

$$
\mathrm{Ce}(\mathrm{IV})+\mathrm{S} \cdot \longrightarrow \mathrm{Ce}(\mathrm{III})+\mathrm{CO}_{2}+\mathrm{H}^{+}
$$

The rate constant of this reaction has been reported as $k_{6 \mathrm{c}}=1 \times 10^{6} \mathrm{M}^{-1} \mathrm{~s}^{-1} \cdot{ }^{13}$ The reactions R6b and R6c might coexist and changes in their relative rates would not lead to differences in the stoichiometry of $\mathrm{CO}_{2}$ production. For a reliable classification of oxalic acid to either the mechanism R5a/R5b or R6a/R6b/R6c additional information on the involved radical(s) is necessary. 
Although it is well-known that molecular oxygen can influence the kinetics of the oxidation of organic acids, only little data is available on details of the underlying complex reaction mechanisms. The presented changes of stoichiometry (Table I) from anaerobic to aerobic reaction conditions should apply additional data to elucidate this problem. In the case of the aerobic oxidation of malonic acid an increase of the stoichiometry from about zero to approximately 0.5 is observed. This change can be explained in terms of the following two reactions, which are a subset of standard autooxidation mechanisms [1,2]:

$$
\begin{aligned}
\mathrm{R} \cdot+\mathrm{O}_{2} & \longrightarrow \mathrm{ROO} \cdot \\
\mathrm{ROO} \cdot+\mathrm{ROO} \cdot & \longrightarrow \mathrm{Q}_{\mathrm{i}}+\mathrm{qCO}_{2}+\mathrm{O}_{2} .
\end{aligned}
$$

The peroxy radical $\mathrm{ROO} \cdot$, which was recently identified for the ceric oxidation of malonic acid [4], undergoes radical recombination (R7b) and splits off $q$ molecules of carbon dioxide. For malonic acid q is found to be approximately one (cf.; Table I). Consequently, this result suggest that the stable fragments $\mathrm{Q}_{\mathrm{i}}$ cannot be tartronic acid $\left(\mathrm{HC}(\mathrm{OH})(\mathrm{COOH})_{2}\right)$ and mesoxalic acid $\left(\mathrm{CO}(\mathrm{COOH})_{2}\right)$, since in this case one would find $\mathrm{f}=\mathrm{q}=0$. In the framework of $\mathrm{R} 7 \mathrm{~b}$, however, it seems reasonable to conclude that either tartronic acid and glyoxylic acid $(\mathrm{HCOCOOH})$ or mesoxalic acid and hydroxyacetic acid $\left(\mathrm{H}_{2} \mathrm{C}\right.$ $(\mathrm{OH}) \mathrm{COOH})$ are produced, because both product pairs correspond to a $\mathrm{q}$ value of 1 (i.e.; $\mathrm{f}=0.5$ ).

The interesting oxygen-dependent increase of stoichiometry found for citric acid and especially mesoxalic acid (anaerobic: 0.55; aerobic: 1.97) illustrates the complexity of the studied oxidation reactions. One possibility to summarize the reaction of mesoxalic acid (MOA) in the presence of oxygen is as follows:

$$
\begin{aligned}
2 \mathrm{Ce}(\mathrm{IV})+ & 2 \mathrm{MOA} \longrightarrow 2 \mathrm{Ce}(\mathrm{III}) \\
& +2 \mathrm{H}^{+}+4 \mathrm{CO}_{2}+\mathrm{HC}(\mathrm{O}) \mathrm{HCO} .
\end{aligned}
$$

However, the presented results require further studies, preferably utilizing EPR spectroscopy and analytical methods, such as HPLC. Also, the oxygen-induced decrease of $\mathrm{CO}_{2}$ production observed in the ceric oxidation of oxalic acid is an intriguing finding that deserves further experimentation. Although these reactions are difficult to explain at this point of our investigations, they stress the usefulness of the presented approach: The analysis of $\mathrm{CO}_{2}$ stoichiometry under excess organic acid conditions allows to distinguish between different reaction schemes and to find unusual behavior that deserves thorough investigations. The presented results also reemphasize that molecular oxygen acts not necessarily as a simple catalyst but introduces oxygen-specific reaction pathways and intermediates.

This research was supported by the Deutsche Forschungsgemeinschaft, the Florida State Univesity, and the NATO Scientific Affairs Division.

\section{BIBLIOGRAPHY}

1. W. H. Richardson, in Organic Chemistry, A. T. Blomquist, Ed., Academic Press, New York, 1965, Vol. 5, K. B. Wiberg, Ed., Part A, Chap. IV, pp. 244.

2. J.-J. Jwo and R. M. Noyes, J. Am. Chem. Soc., 97, 5422 (1975).

3. Y. Gao, H.-D. Försterling, Z. Noszticzius, B. Meyer, J. Phys. Chem., 98, 8377 (1994); A. Sirimungkala, H.-D. Försterling, Z. Noszticzius, J. Phys. Chem., 100, 3051 (1996).

4. B. Neumann, S. C. Müller, M. J. B. Hauser, O. Steinbock, R. H. Simoyi, N. S. Dalal, J. Am. Chem. Soc., 117, 6372 (1995).

5. B. Neumann, O. Steinbock, S. C. Müller, and N. S. Dalal, J. Phys. Chem., A101, 2743 (1997).

6. R. J. Field and M. Burger, Eds., Oscillations and Traveling Waves in Chemical Systems, Wiley-Interscience, New York, 1985; for oxygen effects in the BelousovZhabotinsky reaction see, e.g.: P. Ruoff, and R. M. Noyes, J. Phys. Chem., 93, 7394 (1989); R. M. Taylor, B. R. Johnson, and S. K. Scott, J. Chem. Soc., Faraday Trans., 94, 1029 (1998).

7. S. Barkin, M. Bixon, R. M. Noyes, and K. Bar Eli, Int. J. Chem. Kinet., 10, 619 (1978).

8. D. C. Harris, in Quantitative Chemical Analysis, 4th ed., W. H. Freeman and Company, New York, 1995.

9. H.-D. Försterling, R. Pachl, and H. Schreiber, Z. Naturforsch, 42a, 963 (1987).

10. W. D. Maxon and M. Johnson, Anal. Chem., 24, 1541 (1952).

11. For a recent kinetic study on glyoxylic acid including EPR experiments see: B. Neumann, O. Steinbock, S. C. Müller, and N. S. Dalal, J. Phys. Chem., 100, 12342 (1996)

12. R. J. Field and P. M. Boyd, J. Phys. Chem., 89, 3707 (1985).

13. J. D. Ellis, M. Green, G. Sykes, G. V. Buxton, and R. M. Sellers, J. Chem. Soc., Dalton Trans., 1724 (1973). 